\title{
SERÁ O PÓS-CAPITALISMO CONTEMPORÂNEO UM NOVO SITUACIONISMO?
}

\author{
[IS CONTEMPORARY POSTCAPITALISM A NEW SITUATIONISM?]
}

\author{
Eurico Carvalho * \\ Universidade do Porto, Portugal
}

\begin{abstract}
Resumo: Aparentemente, é neo-situacionista o movimento pós-capitalista. Com vista à prova desta afirmação, aduz-se, em suma, o que os media dizem ser a «economia de partilha». De facto, os pós-capitalistas propõem uma interpretação das novas tecnologias da informação e da comunicação que lhes permite postular que elas acarretam a possibilidade de organizar a produção de um modo descentralizado, ou seja, sem recurso à hierarquia. Deste ponto de vista, o desenvolvimento da produção colaborativa já não obedece às forças do mercado nem à gestão empresarial. Mas o que parece ser evidente não o é, porque, na sua essência, a base da economia de mercado mantém-se enquanto tal. Efectivamente, o sistema capitalista do nosso tempo, isto é, o pós-fordismo, apropria-se da chamada «economia de partilha».
\end{abstract}

Palavras-chave: Capitalismo; fordismo; pós-capitalismo; pós-fordismo; situacionismo

\begin{abstract}
It may seem that the post-capitalist movement is a neo-Situationist one. The evidence for this is, in short, what the media has been called "sharing economy". In fact, the post-capitalists offer an interpretation of the new information technologies in order to postulate that these make it possible to organize production in a not centralized and hierarchical way. From this point of view, the increase of collaborative production no longer responds to the market forces or to the managerial organization. However, I shall argue that what seems to be the case, in reality, turns out to be different, because, deep down, the ground of the market economy has not changed. Actually, the capitalism system of our times, that is, the post-Fordism, takes over the so-called "sharing economy".
\end{abstract}

KeYwORDS: Capitalism; Fordism; postcapitalism; post-Fordism; Situationism

o horizonte da imaginação social, a Internacional Situacionista (1957-1972)
[doravante: I.S.], tendo-se oposto simultaneamente ao marxismo-leninismo e ao neoliberalismo, quis ser a vera vanguarda que encarnava revolucionariamente uma «hipótese comunista» libertária. E, se bem que seja hoje inegável o fracasso da sua pretensão revolucionária, de que Maio de 1968 constitui o «canto do cisne», nada legitima a tentativa revisionista de inferir daí um prejuízo automático para a hipótese enquanto tal (cf. BADIOU, 2009: 12). Está sempre aberta, portanto, a possibilidade histórica da sua reactualização.

* Doutor e colaborador do Gabinete de Filosofia Moderna e Contemporânea do Instituto de Filosofia da Faculdade de Letras da Universidade do Porto (Portugal). E-mail: euricodecarvalho@gmail.com 


\section{Situacionismo e Pós-Capitalismo}

Dessa abertura — perguntar-se-á — serão já sinais «situacionistas» a chamada «economia de partilha» e a multiplicação de estratégias de ludificação da existência? Antes de formularmos, porém, um juízo definitivo sobre o real significado desses «sinais», havemos também de averiguar a plausibilidade do argumento pós-capitalista acerca da «comunidade dos bens comuns colaborativos» (RIFKIN, 2014: 11), que implica necessariamente a desvalorização da concorrência [«a melhor maneira Hayek dixit — de orientar os esforços individuais» ${ }^{1}$ (1944: 63)] em prol da comunicação interpessoal e gratuita. Sabemos, pelo menos, que é esta comunicação, enquanto acção autêntica, que potencia precisamente, para os situacionistas, a criação de situações e a formação de um espaço comunitário. Até que ponto, no entanto, são convergentes o pós-capitalismo, de que hoje se nutre bastamente o discurso utópico, e o situacionismo? Embora haja convergência estratégica relativamente à finalidade última dos respectivos projectos, ou seja, a superação do capitalismo, divergem em relação à hipótese instrumental: ao invés dos pós-capitalistas, que elegem a tecnologia [da informação, em especial (cf. MASON, 2015: 183)] como o veículo da transformação revolucionária da economia (cf. id.: 17), Debord desconfia sobremaneira desse «marxismo das forças produtivas», com a consequente valorização do papel histórico da luta de classes. Daí que recuse, em nome da revolução, quaisquer soluções reformistas [e nestas, naturalmente, não deixaria de incluir o novel «reformismo revolucionário» (id.: 394), i.e., o pós-capitalismo)]. Mas isso não invalida, à partida, a existência de traços programáticos comuns: $(i)$ a negação da hierarquia como princípio de organização social (cf. id.: 22); (ii) a apologia antimercantil da produção colaborativa e gratuita (cf. id.: 207); e (iii) a desvalorização do trabalho em prol do lazer (cf. id.: 220). Estamos perante directrizes que já se subsumem, segundo os pós-capitalistas, sob a figura reticular da «economia de partilha» (id.: 20), cuja condição de possibilidade é, sem dúvida, a tecnologia da informação (cf. RIFKIN, 2014: 43).

Dar-se-á o caso, então, de que essa potenciação económica das «redes sociais», que se alargam exponencialmente, corresponde, enfim, à realização do ideal de uma sociedade cooperativa e igualitária? Contra a corrente das expectativas dos póscapitalistas (cf. MASON, 2015: 228), a resposta deve ser negativa. Vejamos porquê: historicamente, à colonização capitalista do espaço — a industrialização do mundo sucede a do tempo, i.e., a comercialização do lazer. Por outras palavras: como o capitalismo se alimenta do que lhe é exterior (do saque das colónias, por exemplo, à «lavagem» do cérebro), apenas sobrevive com a criação de novos mercados. Neste sentido, trata-se de uma necessidade estrutural, da qual Rosa Luxemburgo tem o mérito, entre os marxistas, de ter previsto - pela primeira vez — os seus efeitos destruidores, quer ambientais quer culturais (cf. LUXEMBURGO, 1913: 467). No entanto, a sua argumentação fica aquém da capacidade de adaptação do capitalismo, porquanto lhe falta o reconhecimento de que a criação de novos mercados não está sujeita aos limites espaciais (cf. id.: 114-116). Desta ilimitação, na realidade, temos o testemunho da «economia de partilha», porque ela explora [conformemente ao princípio neoliberal da desregulação do trabalho (cf. id.: 157)] a totalidade do tempo disponível do indivíduo, transformando-o, como diria Foucault, num «empresário de si mesmo» (2004: 286). Aquilo que agora se designa por «empreendedorismo» contribui objectivamente, destarte, para o desvanecimento das fronteiras relativas ao lazer e ao labor. Impõe-se, todavia, o corolário de que esse desvanecimento não se traduz numa ludificação situacionista da actividade livre. Pelo contrário, ganha a máxima pregnância (particularmente, com o alargamento debordiano da noção clássica de proletariado) a 
tese neomarxista de Hardt e Negri: «A sociedade tornou-se uma fábrica» (2012: 11) [com a notável disseminação de uma nova versão do lumpemproletariado: o «precariado $\rangle^{2}$ ]. Do capitalismo industrial ao financeiro, intensificam-se, por conseguinte, os mecanismos de defesa do capitalismo, cuja acumulação de riqueza já não se cinge à exploração da mais-valia (cf. MASON, 2015: 55), assentando crescentemente [em consonância com a erosão das magnitudes salariais e o correlativo incremento do recurso compensatório ao crédito (cf. id.: 320)] em complexos esquemas rentistas (cf. id.: 167). [Aqui se comprova, como se vê, o carácter ilusório do remédio anticapitalista de Keynes: a «eutanásia do rentier» (1936: 358).] Por outro lado, também se intensifica a consciência da alienação dos trabalhadores: da dependência do salário à dívida, eis a vida toda sujeita à escravidão do dinheiro. Tal intensificação advém, por certo, da crítica que ascende a Marx, mas cujos herdeiros antileninistas (de Rosa Luxemburgo a Guy Debord) não se coíbem de abjurar da fossilização escolástica do seu pensamento. Desta desinibição intelectual faz prova, como sabemos, o conceito nuclear de espectáculo, de acordo com o qual Debord dilui, de algum modo, por força da interpenetração crescente das esferas da produção e do consumo (cf. MASON, 2015: 223), a distinção categorial, de raiz marxista, entre infra-estrutura e superstrutura. Neste contexto, opõe-se ao determinismo económico, que é próprio do marxismo ortodoxo, mas também se afasta (apesar da aparência positivista das primeiras proposições situacionistas acerca do impacto libertário da automatização do processo produtivo ${ }^{3}$ ) de todo o determinismo tecnológico, de que o pós-capitalismo constitui, até à data, o derradeiro avatar. Ainda que seja verdadeira, ademais, a tese sobre a natureza anticapitalista da tecnologia da informação, com a consequente assunção da ideia de que lhe corresponde tendencialmente, ao invés de qualquer outro dispositivo da história, o impulso para a destruição do mercado, da propriedade privada e da relação entre trabalho e salário (cf. ibid.), torna-se inevitável esse afastamento, porque, em si mesma, a informação não é comunicação — nem as «redes sociais» são a expressão autêntica de um ethos comunitário. Além disso, o programa da I.S. não prevê simplesmente a rasura do nexo entre o salário e o trabalho, mas, antes, a simultânea abolição de ambos. À mistura pós-capitalista de labor e lazer (cf. id.: 228), por consequência, não pode corresponder o ideal situacionista da actividade livre, de que o jogo, de facto, se institui como o vero elemento. Realizá-lo-á, porventura, a ludificação global da vida contemporânea? Novamente, não. Da «disneylandização» turística das cidades à «realidade aumentada» ${ }^{4}$, passando pela mistura a que acima nos referimos, são muitas, com efeito, as vertentes de tal ludificação, mas sustentam tão-somente a lógica anti-situacionista da infrene espectacularização do quotidiano. Nem sequer deveríamos falar de uma «ludificação do trabalho». Trata-se, inversamente, da exploração laboral do homo ludens (cf. HAN, 2014: 59). Além disso, o projecto pós-capitalista representa um recuo, do ponto de vista utópico, relativamente ao programa da I.S., porquanto admite, desde logo, a possibilidade de uma coexistência (inicial, pelo menos) entre o sistema de mercado e a «comunidade dos bens comuns colaborativos» (cf. RIFKIN, 2014: 331-332; $v d$. igualmente MASON, 2015: 366). Daqui resulta um hibridismo económico incompatível, realmente, com a radicalidade programática dos situacionistas.

\section{2. О Hомо DigitaLIS}

Pese embora a admissão desse hibridismo, trata-se, em tese, de uma fase transitória (cf. RIFKIN, 2014: 11-12). Quer isto dizer que os pós-capitalistas concordam 
tacitamente com a ideia adorniana de um «capitalismo tardio», justificando-a, desde logo, com a denúncia de que existe, em tal regime económico, uma contradição fatal: a incompatibilidade estrutural entre a tecnologia da informação, enquanto dispositivo capaz de disponibilizar bens e serviços de uma forma tendencialmente gratuita, e a ordem mercantil, cuja lógica reflecte o funcionamento automático do mecanismo concorrencial relativo à formação dos preços. [Deste ponto de vista, a constituição de monopólios surge, então, como a única defesa possível do capitalismo ${ }^{5}$ (cf. MASON, 2015: 193).] Mas a assunção dessa incompatibilidade, por outro lado, não deixa de padecer de um grande equívoco: a confusão entre informação e conhecimento. Não é o mesmo, obviamente, aceder à informação sobre algo e possuir, de um modo concomitante, a compreensão viva e plena do que lhe diz respeito. Ora, por força do obscurecimento da natureza diferencial desses processos mentais, gera-se uma ilusão epistemológica (especialmente nefasta, aliás, sob a perspectiva de uma valorização do saber). É neste contexto, deveras ilusivo, que se invoca a presença, à escala da história da humanidade, de uma novidade absoluta: o desenvolvimento de uma «inteligência colectiva», cuja expressão seria a rede de conexões resultantes da interacção de milhões de cibernautas, assimilando-a, por conseguinte, a uma espécie de "cérebro global» [como se fosse, enfim, a realização virtual do «intelecto geral» de Marx (cf. id.: 218)]. A tudo isto subjaz, no entanto, num domínio antropológico, estoutra crença ilusória: a de que todos os utentes do ciberespaço se encontram num mesmíssimo horizonte, quer intelectual quer volitivo. (Não sendo assim, na realidade, não surpreende que essa ágora planetária seja também o território da desinformação - e da irrelevância cognitiva e social de muitos dos seus conteúdos.)

Além disso, assistimos à emergência do homo digitalis, de que os pós-capitalistas, conformemente às suas ilusões, pretendem fazer o «homem novo», i.e., que há-de substituir o proletariado ( $\mathrm{cf}$. id.: 325). Não lhe parece caber, porém, tal estatuto de agente histórico, porquanto é extremamente volátil a solidariedade orgânica que os ideólogos da interactividade virtual querem adscrever às «redes sociais», sucumbindo, de facto, aos interesses narcisistas e exibicionistas dos respectivos utilizadores (cf. HAN, 2013: 21-26), os quais são indiferentes, o mais das vezes, à própria maximização empresarial dos «megadados» oriundos das suas interacções digitais (cf. RIFKIN, 2014: 351). Quanto à veste auto-suficiente de «prossumidor»" também não lhe cabe, visto que implica que se tome como uma evidência a chamada «sociedade do conhecimento», o que não é, de todo, o caso (cf. CHANG, 2014: 337). $\mathrm{Na}$ verdade, o homo digitalis continua a ser um espectador — ou, melhor dizendo, um hiperespectador, i.e., cuja "sobrevivência aumentada» já corresponde, portanto, à «realidade aumentada». E se bem que tenha um inegável colorido situacionista a luta que o pós-capitalismo elege como o motor da mudança, ou seja, a que confronta a rede com a hierarquia (cf. MASON, 2015: 25), não se trata de uma luta de classes, não podendo nós tomar como uma espécie de neo-situacionismo, consequentemente, o projecto pós-capitalista, para o qual pesa mais a organização do modo de produção (vertical? lateral?) do que a natureza da propriedade (pública? privada?) dos seus meios. Mas, apesar de não ser substancial, do ponto de vista da crítica marxista da economia política, a presente distinção conceptual, permite ao pós-capitalista, pelo menos, fazer o processo do industrialismo, cujo modelo hierárquico de produção engloba, segundo ele, tanto o regime «capitalista» quanto o «socialista» (cf. RIFKIN, 2014: 116). Sabemos que este último, contudo, não deixa igualmente de ser, para Debord, uma forma - burocrática - de capitalismo, confirmando-se, assim, a radicalidade do programa situacionista. 


\section{A Rejeição do Crescimentismo}

Independentemente dos contrastes que estabelecemos, tanto o situacionismo como o pós-capitalismo assentam o seu modelo de transformação social num pressuposto comum: a passagem da era da escassez para a da abundância (cf. DEBORD, 2006: 309-310; vd. RIFKIN, 2014: 28; e vd. igualmente MASON, 2015: 362). E, o que não é de somenos, tanto um como outro subscrevem a tese escatológica - do cunho crepuscular do actual capitalismo (cf. DEBORD, 2006: 1066; $v d$. RIFKIN, 2014: 12; e vd. igualmente MASON, 2015: 18), cujo modo de produção se distingue historicamente pelo facto (inédito, à luz do passado) de correr o risco de ter crises em fases de crescimento (cf. MASON, 2015: 100). Ambos rejeitam igualmente o paradigma crescimentista que faz parte da sua natureza, da qual decorre, em suma, o desenvolvimento automático e monótono, i.e., quantitativo, das forças produtivas (cf. DEBORD, 2006: 1065). Dessa rejeição, ademais, a base argumentativa, que é dupla, possui os mesmos pilares: de um lado, a preocupação ecológica; e, do outro, a subversão da centralidade sociocultural do trabalho. Associam-se à revolução, concomitantemente, não só a preservação da biosfera (cf. id.: 1063-1069; e vd. RIFKIN, 2014: 511-552), mas também a demonstração do «carácter lúdico da comunidade dos bens comuns colaborativos» (RIFKIN, 2014: 232), cuja versão situacionista [a realização «pós-industrial» do jogo e da arte (cf. DEBORD, 2006: 1025)] pressupõe, porém, para este último, o advento da sociedade sem classes. Quanto à condenação debordiana do capitalismo, não devemos esquecer, todavia, que ela extravasa a «questão social». Mais do que a exploração dos trabalhadores, com efeito, o que preocupa Guy Debord, à margem do marxismo ortodoxo, prende-se, acima de tudo, com o bloqueio capitalista da criatividade. Nesta abordagem crítica, de resto, também se revê uma certa perspectiva pós-capitalista, cuja análise do neoliberalismo acentua precisamente o seu cerco monopolista à inovação (cf. MASON, 2015: 425) [com o consequente freio ao desenvolvimento qualitativo das forças de produção (cf. DEBORD, 2006: 1065)]. Nem sequer colhe o beneplácito dos pós-capitalistas — que não são anticapitalistas - o contra-argumento clássico, i.e., que assenta a defesa do capitalismo na ideia de que se trata do único sistema capaz de promover a invenção de novos produtos e serviços (cf. RIFKIN, 2014: 47-48). De mais a mais, a verdadeira inovação vai muito além dos gadgets, de que Debord, desde logo, não ignora o papel espectacular (2006: 1017), i.e., «o que define o homem no capitalismo moderno: o seu dever de consumidor» (id.: 1019).

Não obstando à pertinência dessas aproximações, não se veja nelas, todavia, matéria bastante para reduzir o pós-capitalismo a uma variante digital do situacionismo, i.e., que trata as «redes sociais», e já não os núcleos conselhistas, como a verdadeira força motriz da mudança. Seria uma caricatura que nem sequer poderíamos acolher cum granus salis. Até importa frisar que alguns pós-capitalistas compreenderam cabalmente o papel contra-revolucionário da desvalorização neoliberal do trabalho (cf. MASON, 2015: 157-159), tendo sido postos a salvo, portanto, das ilusões do keynesianismo. Ora, aí está, no entanto, o que Guy Debord não soube ver. Por isso mesmo, é preciso sublinhar a sua «cegueira». Apesar de ser incontornável esse sublinhado, talvez se possa, mesmo assim, pôr o problema de saber se tal "cegueira», num contexto keynesiano, possui alguma razoabilidade. Devemos admitir que sim, pelo menos, no que respeita à «terciarização» da economia, ainda que a análise debordiana, à luz d'O capital, não seja assaz fina, não acolhendo sequer, por exemplo, a distinção que Marx estabelece (polemicamente, embora ${ }^{7}$ ) entre trabalhadores produtivos e «improdutivos» 
(e entre estes últimos estão precisamente os trabalhadores dos serviços). Relativamente àqueles, que compõem o núcleo da indústria, verifica-se, em verdade, o aumento tendencial do número dos que trabalham «improdutivamente», i.e., cujo labor, embora seja objecto de consumo por parte do capitalista, não se consome, para Marx, segundo a lógica do capital, mas tão-somente como valor de uso, não havendo, pois, produção de mais-valia. Se é esse o caso, realmente, estamos perante uma actividade que acarreta, para as empresas, um «falso custo», de que elas, já no quadro neoliberal da polivalência funcional, buscam livrar-se, com a consequente redução do respectivo impacto financeiro. Nesse ensejo, designadamente, podem atribuir ao trabalhador produtivo (em especial, feminino) tarefas que excedem o seu leque especializado de competências (como é o caso das que são habitualmente prerrogativa das empregadas de limpeza e porteiras), o que implica, por certo, uma crescente exploração da força laboral. Debord, porém, que então ideava - à margem desses lugares-comuns marxistas — sob o influxo da revolta de Maio, não soube antecipar o resgate axiológico desse movimento pelas novas formas de organização do trabalho. $\mathrm{Na}$ sua fase «toyotista», de facto, o capitalismo, explorando o trabalho imaterial com base no surto das tecnologias de informação e comunicação, passa a incorporar os valores de 1968, de que o binómio «imaginação-autonomia» constitui a melhor súmula. Por isso, pondo em questão a «cegueira» debordiana, haveria que perguntar: Quais são os empregos que os trabalhadores já não querem ter? Quais são os bens de consumo que eles já não querem comprar? Dentro dos limites eurocêntricos em que se inscreve o erro keynesiano de Guy Debord ${ }^{8}$, só poderíamos responder cruamente: não querem empregos fordistas nem produtos estandardizados. Mas esses trabalhadores não são certamente emigrantes - nem laboram nas fábricas deslocadas do Ocidente.

Destarte, juntamente com o eurocentrismo (e o correlativo ocultamento de traços típicos da globalização: as deslocalizações e a desindustrialização parcial do Norte), temos uma crítica do trabalho que muito deve à vigência do paradigma funcional da linha de montagem, e cujo ícone anticapitalista, que data de 1936, da autoria de Charlie Chaplin, continua a ser o filme Tempos modernos. (O seu primeiro minuto contém, como sabemos, uma sequência antológica, na qual, sob o influxo dialéctico da montagem paralela, se torna visível a «animalização» dos trabalhadores.) Na realidade, à radical oposição situacionista entre criatividade e trabalho não é indiferente o clássico modelo ocidental do desempenho laboral, ou seja, o fordismo, na sua versão taylorista (cf. VANEIGEM, 1967: 70-71). Todas as características que moldam o perfil industrial que lhe é intrínseco (a mecanização, a especialização, a separação entre quem pensa e faz, a parcelarização e repetição das tarefas e, ainda, o isolamento do ambiente fabril) são a negação, para Debord, de uma acção verdadeiramente livre, i.e., própria da humanidade do homem. Em que medida, contudo, o toyotismo — perguntar-se-á — pode pôr em xeque a radicalidade evidente dessa antinomia entre criação e laboração? Não sendo simples nem imediata, a resposta exige uma série de esclarecimentos prévios. Por ser nipónica, antes de mais, a origem de tal processo de gestão empresarial, a sua ocidentalização, que acompanha a desregulação neoliberal dos mercados, não avança sem dificuldades e, consequentemente, sofre algumas adaptações. Entre as primeiras, naturalmente, devemos situar a necessidade de articular a unidimensionalidade fordista da cadeia de comando industrial com a horizontalização toyotista da produção, que se faz sob o signo do trabalho cooperativo (cf. ANTUNES, 1999: 86-87); e, entre as segundas, merece realce a recusa da implantação da regra japonesa relativa à natureza vitalícia do vínculo laboral de uma parte significativa dos trabalhadores (cf. id.: 83). Nesta recusa, temos a prova do que Wolfgang Streeck diz ser a tendência finissecular, que hoje se mantém e agudiza, para tolerar cada vez mais a 
incerteza subjacente às flutuações da oferta e da procura (2013: 66). Assistimos a uma surpreendente dulcificação cultural do risco, dando-se-lhe a aura juvenil e hollywoodesca da aventura, que contrasta fortemente com a segurança de uma carreira profissional sob a tutela de uma negociação colectiva. Com tudo isto, no entanto, o que se pretende, afinal, não é senão eludir o carácter perverso das consequências sociais da precariedade dos empregos. O que ressalta das profundezas desta análise, todavia, não é essa elusão, mas a surpresa de vermos a funcionar a neutralização neoliberal do que passa por ser, para Karl Polanyi, «o ponto de Arquimedes» das economias de mercado - a sua incerteza estrutural ${ }^{9}$ — , e de acordo com a qual, realmente, o keynesianismo pode emergir, segundo Debord, por força do entrosamento do Estado com a economia, como o grande mecanismo de defesa do capitalismo. Contra as expectativas de toda a teoria crítica, porém, não só o sistema capitalista sobrevive à morte de Keynes, mas também reforça o seu domínio sobre o mundo.

\section{A Versão Toyotista do Capitalismo}

Com o toyotismo, intenta-se a prevenção de qualquer crise de legitimação do capitalismo em nome de uma ideia-chave: em vez de serem «peças substituíveis» (CHANG, 2014: 202), os trabalhadores devem agir como colaboradores da empresa, tornando-se cúmplices, portanto, das disposições laborais que lhes dizem respeito. Trata-se de uma estratégia de gestão que pretende bloquear, desde logo, com o discurso do envolvimento subjectivo de quem trabalha (cf. ANTUNES, 1990: 90), quaisquer potenciais focos de conflito. Para os regular, também se aposta num sindicalismo local, i.e., circunscrito à própria esfera do grupo empresarial, de forma que erradique, de vez, o horizonte político da luta de classes. Além disso, e num registo contrastante com o fordismo, outros aspectos há que particularizam a organização toyotista do trabalho (cf. $i d .: 54)$, de que urge salientar, pelo menos, três itens: $(i)$ a redução estrutural do número de hierarquias; (ii) a promoção do espírito de equipa; e (iii) a aproximação intelectual e funcional das fases extremas da produção, i.e., a ideação e a execução. Á primeira vista, o que nos chama a atenção é o facto de termos aqui, aparentemente, um conjunto de linhas tendenciais de desenvolvimento do que, aquando da sua hipotética plenificação, poderíamos qualificar como uma actividade situacionista. A aparência desfaz-se, porém, quando se confronta a abstracção dos traços típicos da produção pós-fordista com a sua alienação subjectiva. Embora se assista à crescente subtilização das suas formas expressivas (designadamente, a passagem da dialéctica do ter à do parecer), cujo clímax coincide com a oficialização sociológica e académica da respectiva inexistência [cf. STREEK, 2013: 45 (n. 15)], continua a ser inautêntica (cf. ANTUNES, 1998: 224), de facto, a subjectividade que corresponde às exigências infinitas (no mau sentido do termo, diria Hegel) de valorização do capital. Também sabemos que essa subtilização se torna mais fácil e insidiosa com o progresso da imaterialização do trabalho e o crescimento do valor das competências pessoais (soft skills) relativamente às técnicas (hard skills). Na era informática da forma-mercadoria (cf. ANTUNES, 2007: 259), que conduz à sua espectacularização total, a chamada «interactividade», que é própria do mundo digital, acentua, sem dúvida, a natureza alienante do trabalho abstracto (cf. id.: 260). Essa acentuação, que é hoje (em pleno pós-fordismo) inegavelmente manifesta, não escapa, ademais, ao autor d'A Sociedade do Espectáculo, cuja crítica da instrumentalização maquínica da linguagem, enquanto negação cibernética da autenticidade da comunicação humana, remonta, pelo menos, a 1963 (cf. DEBORD, 2006: 613-619). [Muito antes, todavia, e num outro plano, i.e., histórico-fillosófico, já a 
Escola de Frankfurt fizera a denúncia - antipositivista — da redução da linguagem à condição ancilar de instrumento, para a qual apela, aliás, o desenvolvimento científico-industrial (cf. HORKHEIMER, 1947: 29).] Num vocabulário situacionista, o reverso utópico da alienação não é senão a plenitude grega e lúdica da poesia (cf. HUIZINGA, 1938: 183), i.e., a correspondência mútua de um dizer que se faz e de um fazer que se diz. Trata-se, então, de uma correspondência impensável à luz de um regime socioeconómico que se alimenta da dissociação irreversível e mercantil do ser e do parecer. Apesar da redução toyotista da distância aparente entre pensamento e acção, a resposta à questão que acima formulámos só pode ser, portanto, para Debord, a reafirmação da oposição radical entre criatividade e trabalho, de que aquela diminuição fenoménica seria apenas uma superação falaciosa. Quanto à possibilidade de existir uma que não o seja, eis o que implica, desde logo, relativamente à I.S., a explosão do seu quadro programático.

Deve-se, em grande medida, à actual preponderância teórica da abordagem neoclássica da economia, cuja análise elege como objecto o domínio da troca e do consumo, a desvalorização do sector secundário (cf. CHANG, 2014: 26), de acordo com a qual se assiste, desde os últimos decénios do século XX, à propagação mediática da ideia de um capitalismo «pós-industrial». Embora não se trate, do ponto de vista do emprego da força laboral do Ocidente, de uma etiqueta desajustada à realidade, justificando-se assim, de algum modo, o seu uso, não podemos ignorar os seus limites (cf. id.: 210-213). Na verdade, o reino da produção, conformemente à lição de Marx, continua a ser fundamental. Mais: «O sector secundário tem sido o "centro de aprendizagem" do capitalismo» (id.: 209). Que melhor demonstração desta tese podemos ter do que a transformação, que acima descrevemos, do regime serial de produção? Neste sentido, a linha de montagem mantém-se, à revelia dos discursos rizomáticos e pós-modernos, como a «espinha dorsal» (id.: 201) do sistema produtivo do capitalismo, tanto mais que os processos de organização industrial (e, em particular, os advindos da passagem do fordismo para o toyotismo) se transferem facilmente para outros sectores económicos [como é o caso dos serviços, de que são exemplo as cadeias de restauração de «comida rápida», cuja confecção de refeições segue os princípios da produção em série (cf. id.: 210)]. Consequentemente, a crítica novecentista do industrialismo, que podemos remontar à obra de Horkheimer, não perdeu a sua pertinência histórico-filosófica. Enquanto herdeiro dessa linhagem anti-industrialista, que lhe valeu, de resto, a ruptura com a «ala artística» da I.S., Debord tornou-se, como sabemos, um dos maiores intérpretes dos efeitos existenciais e estético-políticos da industrialização da vida social. E entre eles, desde logo, devemos assinalar a massificação do gosto (da fast food ao kitsch) e, ainda, a privatização do espaço público, de que é responsável, em parte, a «ditadura do automóvel», cuja desmontagem situacionista se articula, ademais, com a defesa de um novo urbanismo.

Para a compreensão desses efeitos, há que enquadrá-los à luz da seguinte interrogação: Será que a negação industrialista do sujeito pode ter por compensação a organização racional da sociedade moderna? À semelhança do autor desta pergunta (cf. HORKHEIMER, 1947: 170-171), Debord responder-lhe-ia negativamente, porque nele, contrariamente à maioria das pessoas, o mimetismo, enquanto desejo de adaptação à realidade, não se sobrepõe à vontade de «fazer história». É, pois, Guy Debord, conclusivamente, uma «personalidade», no preciso sentido em que, segundo Horkheimer, a generalidade dos indivíduos não a tem (cf. id.: 132). [Não se veja contra-exemplos à tese horkheimeriana nos «ídolos das massas», visto que eles se reduzem, em conformidade com uma crítica que é também a dos situacionistas, às «funções dos processos sociais» (id.: 176).] Quanto ao «núcleo da verdadeira 
individualidade» (id.: 177), em Debord, importa reconhecer, outrossim, na sequência da análise que estamos a seguir, que se trata, abreviando uma expressão de Horkheimer, da «resistência à irracionalidade» (ibid.), cujo veículo metodológico, tanto para um como para outro, não é senão o «trabalho do negativo». Mas, sendo o mesmo o método, o da negação (cf. id.: 200-201), é distinto, naturalmente, o seu objecto directo: num caso, o industrialismo; e, no outro, o espectáculo.

É deveras significativo, por outro lado, que os dois grandes modelos de organização industrial do trabalho devam a sua identidade ao automóvel. Por ser o objecto que singulariza civilizacionalmente o século $\mathrm{XX}^{10}$, não nos surpreende que nele se concentre o vívido desprezo debordiano pelo capitalismo ${ }^{11}$. Como ele simboliza «a derradeira privatização» (RIFKIN, 2014: 387), à sua «ditadura» — a «motorização» da rua (com o consequente rapto do espaço vital que lhe é consubstancial) — subjaz a tábua axiológica adversa à reinvenção situacionista da vida quotidiana, de que a deriva, aventura colectiva e pedestre, constitui uma peça-chave. Contra os valores da circulação (de todos os avatares do capital), o que Debord nos propõe, com o programa da I.S., não é senão a utopia estético-política de uma comunicação total, i.e., autêntica. Mas só aparentemente é marxista a fórmula que explica a autenticidade da vida. Para Debord, de facto, a luta que lhe dá sentido não é (como pensa ainda um discípulo do maior herdeiro húngaro de Lukács ${ }^{12}$ ) «acção de classe do trabalho contra o capital» (ANTUNES, 1999: 112); é, sim, acção de classe contra o trabalho e o capital. Tanto um como outro são tão-somente, do ponto de vista situacionista, as duas faces da mesma moeda falsa, ou seja, a da metabolização social que destrói o homem e a natureza.

\section{REFERÊNCIAS}

As indicações bibliográficas que o texto contém dizem respeito à data da edição original. Nem sempre tivemos, todavia, a possibilidade de recorrer às edições originais. Nesse caso, a paginação remete o leitor para as edições que constam deste acervo bibliográfico.

AA.VV. [1958-1969] — Internacional Situacionista: Antologia. Trad. de Júlio Henriques. Lisboa: Antígona, 1997.

ANTUNES, Ricardo (1999) — Os Sentidos do Trabalho: Ensaio sobre a Afirmação e a Negação do Trabalho. Coimbra: Edições Almedina, 2013.

ANTUNES, Ricardo (2007) — «Dez Teses e uma Hipótese sobre o Presente (e o Futuro) do Trabalho». In op. cit., pp. 253-268.

ANTUNES, Ricardo (2009) — «A Economia Política das Lutas Sociais». In op. cit., pp. 281-288.

BADIOU, Alain (2009) — L'Hypothèse Communiste. Paris: Nouvelles Éditions Lignes.

BARTHES, Roland (1957) — Mitologias. Trad. e prefácio de José Augusto Seabra. Lisboa: Edições 70, 1984.

BAUDRILLARD, Jean (1976) — A Troca Simbólica e a Morte. 2 vols. Trad. de João Gama (rev. por Artur Morão). Lisboa: Edições 70, 1996/1997.

CHANG, Ha-Joon (2014) — Economia: Guia do Utilizador. Trad. de Luís Santos. Lisboa: Clube do Autor, 2016.

DEBORD, Guy (2006) - Euvres. Ed. de Jean Louis Rançon (com a colaboração de Alice Debord). Paris: Gallimard, 2006.

FOUCAULT, Michel (2004) - Nascimento da Biopolítica. Trad. de Pedro Elói Duarte. Lisboa: Edições 70, 2010.

HAN, Byung Chul (2013) - No Enxame: Reflexões sobre o Digital. Trad. de Miguel Serras 
Pereira. Lisboa: Relógio d'Água, 2016.

HAN, Byung Chul (2014) - Psicopolitica: Neoliberalismo e Novas Técnicas de Poder. Trad. de Miguel Serras Pereira. Lisboa: Relógio d'Água, 2015.

HARDT, Michael \& NEGRI, Antonio (2000) — Império. Trad. de Miguel Serras Pereira. Lisboa: Livros do Brasil, 2004.

88 HARDT, Michael \& NEGRI, Antonio (2012) - Declaration. Allen, Texas: Argo Navis.

HAYEK, Friedrich (1944) - O Caminho para a Servidão. Trad. de Marcelino Amaral. Lisboa: Edições 70, 2014.

HORKHEIMER, Max (1947) - O Eclipse da Razão. Trad. de João Tiago Proença. Lisboa: Antígona, 2015.

HUIZINGA, Johan (1938) - Homo Ludens. Trad. de Eugenio Imaz. Madrid: Alianza, 2010.

JAPPE, Anselm (1998) - «Política do Espectáculo e Espectáculo da Política». In Uma Conspiração Permanente contra o Mundo: Reflexões sobre Guy Debord e os Situacionistas. Trad. de Jorge Lima Alves. Lisboa: Edições Antígona, 2014, pp. 13-39.

JORN, Asger (1958) - «Os Situacionistas e a Automatização». In Internacional Situacionista, op. cit., pp. 28-33.

KEYNES, John Maynard (1936) - Teoria Geral do Emprego, do Juro e da Moeda. Trad. de Manuel Resende. Lisboa: Relógio d'Água, 2010.

LUXEMBURGO, Rosa (1913) - The Accumulation of Capital. Trad. de Agnes Schwarzschild. Londres: Routledge \& Kegan Paul, 1951.

MASON, Paul (2015) - Pós-capitalismo: um Guia para o Nosso Futuro. Trad. de Paulo Ramos. Lisboa: Objectiva, 2016.

POLANYI, Karl (1944) - A Grande Transformação: as Origens Políticas e Económicas do Nosso Tempo. Trad. de Miguel Serras Pereira. Lisboa: Edições 70, 2012.

RIFKIN, Jeremy (2014) — A Sociedade do Custo Marginal Zero: a «Internet» das Coisas, a Comunidade dos Bens Comuns e o Eclipse do Capitalismo. Trad. de Sara M. Felício. Lisboa: Bertand Editora, 2016.

STANDING, Guy (2011) - O Precariado: a Nova Classe Perigosa. Trad. de Carlos Braga e Ana Maria Braga. Lisboa: Editorial Presença, 2014.

STREECK, Wolfgang (2013) - Tempo Comprado: a Crise Adiada do Capitalismo Democrático. Trad. de Marian Toldy e Teresa Toldy. Coimbra: Actual Editora, 2013.

VANEIGEM, Raoul (1967) — Traité de savoir-vivre à l'usage des jeunes générations. Paris: Gallimard, 1992.

\section{NoTAS}

1 «O capitalismo fez-nos ver o mecanismo dos preços como a coisa mais orgânica, espontânea e granular da vida económica» (MASON, 2015: 232). A essa "evidência», certamente, não será alheia a preponderância social de uma ilusão epistemológica deveras pregnante: a sobreposição marginalista da esfera nominal dos preços à dos valores, retirando-se a estes últimos, portanto, toda e qualquer substancialidade.

2 Nesse neologismo (resultante da aglutinação de duas palavras: «precário» e «proletariado»), há quem veja, porém, a designação de uma nova classe, distinguindo-a, portanto, do lumpemproletariado (correspondente à camada social mais baixa, segundo o marxismo, do proletariado). (Com vista à ilustração do caso, vd., v.g., STANDING, 2011: 33.) Enquanto tal, contudo, torna-se deveras polémico o termo, que pretende identificar a crescente massa proteiforme de quem trabalha temporariamente, i.e., sem qualquer vínculo laboral estável. Mas esse uso terminológico parece indiciar um discurso algo inconsistente: se o «precariado» é, de facto, uma nova classe - que emerge da globalização - , como se explica que ela se confunda tendencialmente com a maioria dos trabalhadores? Não será preferível falar de um fenómeno global de «subproletarização» e «precarização» do trabalho, com o consequente aumento exponencial do número de lumpemproletários? Destes últimos temos, de resto, como característica central, a ausência de consciência de classe, que se considera ser precisamente, por força da sua 
atomização, a marca servicial do «precariado» (cf. id.: 58). Só é possível que o autor o tome, por outro lado, como um «tipo ideal», à maneira weberiana, porque ele concebe de forma restritiva a noção de proletariado (cf. id.: 28-30). — Independentemente desta crítica, todavia, devemos realçar o mérito da obra de Standing e, em especial, a sua proposta de emancipação da ocupação e do lazer do jugo mercantil do trabalho e do entretenimento (cf. id.: 39). Justifica-se plenamente este realce, porquanto estamos perante uma perspectiva que, ainda que não seja, stricto sensu, situacionista, não deixa de comungar, de algum modo, do espírito antitrabalhista de Guy Debord.

3 Cf. JORN (1958). - Apesar das suas ambiguidades, o artigo de Asger Jorn sobre as virtudes do desenvolvimento tecnológico parece abraçar, por fim, o «marxismo das forças produtivas», do qual, de facto, Guy Debord se afasta tendencialmente. [Quanto a tal afastamento, vd. igualmente JAPPE, 1998: 19 (n.11).] Como indício paradoxal dessa adesão, temos o apreço jorniano pela estandardização, cuja definição se consubstancia nos termos que se seguem: «A ideia de estandardização é um esforço para reduzir e simplificar o maior número das necessidades humanas com a maior igualdade» (JORN, id.: 33). - Eis-nos, sem dúvida, perante a valorização «comunista» de uma ideia que, enquanto tal, apela directamente para o discurso - anti-situacionista - do funcionalismo. Ora, como Jorn se opõe expressamente a tal doutrina, não podemos senão concluir que ele pretende fazer passar por um juízo de facto o que nos diz acerca da estandardização, quando se trata, pelo contrário, de um juízo de valor.

4 Muito antes de se tornar escandalosamente visível o fenómeno da «turistificação» do espaço urbano, já os situacionistas procediam, no quadro do urbanismo unitário, à sua denúncia: «Ao passo que hoje as próprias cidades se oferecem como um lamentável espectáculo, um suplemento dos museus, para turistas que se passeiam em autocarros de vidro, o U.U. encara o meio ambiente como campo de um jogo participativo» [AA.VV. (1958-1969): 53]. - Mais uma vez, aqui temos a prova de que se mantém inteiramente actual a crítica situacionista da vida quotidiana.

5 Com vista à ilustração do monumental poder monopolista das empresas multinacionais, vd. RIFKIN, 2014: 99-101.

6 Trata-se de um neologismo resultante da aglutinação de duas palavras: «produtor» e «consumidor». Com o termo, o pós-capitalista pretende ilustrar a condição «infofabril» de quem consome e partilha os seus próprios produtos (cf. RIFKIN, 2014: 157). Mas estamos perante um conceito polémico, porque lhe corresponde a ideia «robinsoniana» de uma «democratização do fabrico» (id.: 163), cujo alcance efectivo, por agora, porém, parece excessivamente paroquial.

7 É polémica, de facto, tal distinção, porquanto gera, acima de tudo, um duplo paradoxo. Vejamos o primeiro: se o trabalhador «improdutivo» não produz uma mais-valia para o capitalista, isso implica a assunção de que este último não explora aquele, com a consequente negação da universalidade da tese marxista acerca da exploração do proletariado. Vejamos o segundo: «O paradoxo consiste, então, em que, de acordo com a definição de Marx, uma parte crescente do trabalho humano se torna improdutivo sem que isso impeça visivelmente o capital de aprofundar a sua dominação» [BAUDRILLARD, 1976: 36 (I)]. Independentemente de se saber se é possível — ou não — uma resolução marxiana de ambos os paradoxos, a obra de Guy Debord não se deixa afectar, de modo algum, pela existência de tal problema.

9 «A nossa tese - afirma Polanyi — é [a de] que a ideia de um mercado capaz de se auto-ajustar era uma mera utopia» (1944: 120). - Eis uma tese que é hoje digna, sem dúvida, de um inegável crédito intelectual.

10 «Creio que o automóvel é hoje o equivalente bastante exacto das grandes catedrais góticas: quero dizer, uma criação que faz época, concebida com paixão por artistas desconhecidos, consumida na sua imagem, se não no seu uso, por um povo inteiro, que através dela se apropria de um objecto perfeitamente mágico» (BARTHES, 1957: 139). Desta analogia, no entanto, não só devemos realçar a força (a assimilação do automóvel a uma singularidade civilizacional), mas também a fraqueza, ou seja, a insuficiência do símile (a catedral gótica). Se bem que seja o automóvel, enquanto objecto de culto, o pasto que 
alimenta o imaginário colectivo de Novecentos, trata-se de uma alimentação que se faz às avessas do espírito medieval. Em vez do recolhimento comunitário, à luz da religião, impõe-se, em verdade, o regime capitalista da economia política, com a consequente privatização do espaço público.

11 «Se a característica definidora de um sistema capitalista é a propriedade privada, a sua imagem de marca é [efectivamente] o automóvel» (RIFKIN, 2014: 387). Mais: «O século XX, que já se foi, pode ser estampado como o século do automóvel» (ANTUNES, 2007: 253). Mas é esse mesmo século, precisamente, que merece passar para a história como a era americana. Assim sendo, explica-se facilmente a emergência da associação terminológica que se segue: «O próprio termo automóvel invoca a ideia veiculada pela economia clássica de que a natureza humana é orientada pela procura de autonomia e mobilidade, conceitos que os norte-americanos há muito associam à ideia de liberdade» (RIFKIN, 2014: 387). Pese embora a referência à autonomia, que é meramente nominal, trata-se, de facto, de uma liberdade negativa, i.e., que deve o seu conteúdo à ausência de determinações. Como a indeterminação se associa habitualmente a um espaço sem limitações, é o automóvel, sem dúvida, que melhor ilustra, qual potência ocupante, o que se entende por american way of life, com o consequente corolário: «na era capitalista, começámos, erradamente, a definir liberdade como o direito a excluir, e o automóvel tornou-se a representação dessa noção convencional de liberdade» (id.: 388). Que um autor norte-americano - sem simpatias marxistas ou esquerdistas - tenha, afinal, quase meio século após a publicação d'A sociedade do Espectáculo, um ponto de vista sobre o automóvel que vai ao encontro da crítica situacionista, eis o que não poderíamos deixar de assinalar e registar.

12 Ricardo Antunes, marxista brasileiro, e cuja obra tem por grande referência o pensamento de István Mészáros (cf. ANTUNES, 1999: 13). 